\section{BRAZIULIAN JOURNAL}

OF MEDICAL AND BIOLOGICAL RESFARCH

www.bjournal.com.br
ISSN 0100-879X

Volume 43 (12) 1135-1244 December 2010

BIOMEDICAL SCIENCES

AND

CLINICAL INVESTIGATION

Braz J Med Biol Res, December 2010, Volume 43(12) 1215-1224

doi: 10.1590/S0100-879X2010007500119

Evaluation of the immune humoral response of Brazilian patients with Rubinstein-Taybi syndrome

L.C. Torres, S.M.M. Sugayama, C. Arslanian, M.M. Sales and M. Carneiro-Sampaio

The Brazilian Journal of Medical and Biological Research is partially financed by
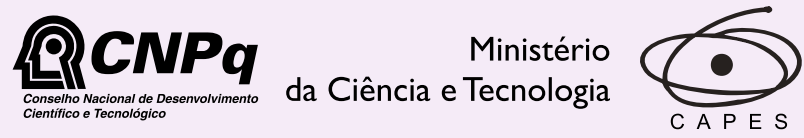

Ministério da Educação

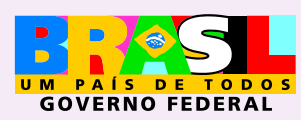

DFAPESP

Institutional Sponsors
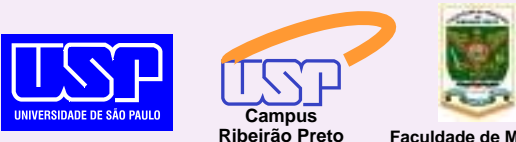

Ф SHIMADZU

GE Healthcare
Hotsite of proteomics metabolomics developped by: 


\title{
Evaluation of the immune humoral response of Brazilian patients with Rubinstein-Taybi syndrome
}

\author{
L.C. Torres ${ }^{1,3}$, S.M.M. Sugayama ${ }^{3}$, C. Arslanian ${ }^{1}$, M.M. Sales ${ }^{2}$ and \\ M. Carneiro-Sampaio ${ }^{3}$ \\ 1Departamento de Imunologia, Instituto de Ciências Biomédicas, \\ Universidade de São Paulo, São Paulo, SP, Brasil \\ 2Divisão de Patologia Clínica, Laboratório de Investigação Médica (LIM 003), \\ Hospital das Clínicas, Universidade de São Paulo, São Paulo, SP, Brasil \\ ${ }^{3}$ Departamento de Pediatria, Laboratório de Investigação Médica (LIM 36), \\ Faculdade de Medicina, Universidade de São Paulo, São Paulo, SP, Brasil
}

\begin{abstract}
Rubinstein-Taybi syndrome (RTS) is a rare developmental disorder characterized by craniofacial dysmorphisms, broad thumbs and toes, mental and growth deficiency, and recurrent respiratory infections. RTS has been associated with CREBBP gene mutations, but EP300 gene mutations have recently been reported in 6 individuals. In the present study, the humoral immune response in 16 RTS patients with recurrent respiratory infections of possible bacterial etiology was evaluated. No significant differences between patients and 16 healthy controls were detected to explain the high susceptibility to respiratory infections: normal or elevated serum immunoglobulin levels, normal salivary IgA levels, and a good antibody response to both polysaccharide and protein antigens were observed. However, most patients presented high serum IgM levels, a high number of total $B$ cell and B subsets, and also high percentiles of apoptosis, suggesting that they could present B dysregulation. The CREBBP/ p300 family gene is extremely important for B-cell regulation, and RTS may represent an interesting human model for studying the molecular mechanisms involved in B-cell development.
\end{abstract}

Key words: Rubinstein-Taybi syndrome; High IgM levels; B lymphocyte; Antibody response

\section{Introduction}

Rubinstein-Taybi syndrome (RTS), a clinically welldefined condition, is a rare developmental disorder characterized by craniofacial dysmorphisms, broad thumbs and toes, and mental and growth deficiency (1). The prevalence at birth is estimated to be 1 in 125,000 liveborn infants (2). RTS usually occurs sporadically although it may be inherited as an autosomal dominant disorder (OMIM 180849) $(2,3)$. The diagnosis is still essentially clinical and has been based on characteristic features (3). The major items to look for in RTS are a beaked nose, grimacing smile, broad thumbs and big toes, and mental retardation (4). The main clinical problems are failure to thrive, congenital heart defects, and recurrent respiratory infections (5). RTS has been associated with mutations of the CREB-binding protein (CREBBP or $C B P$ ) gene, located on chromosome 16p13.3 (6), which have been demonstrated in $45-56 \%$ of RTS patients (7). However, mutations of the EP300 (p300) gene, located on chromosome 22q13.3, were recently identified in six RTS patients $(8,9)$.

A review of 571 RTS cases has demonstrated elevated susceptibility to infections during infancy and childhood (5). The natural course of the disease shows that morbidity is mainly determined by recurrent respiratory infections that were initially attributed to microaspirations consequent to gastroesophageal reflux disease $(1,5)$. However, some investigators have suspected the existence of primary immunodeficiency affected by RTS $(10,11)$.

Ming et al. (12) performed a review of 65 genetic diseases that showed increased susceptibility to infections, and immune disorders were identified in many of them. This

Correspondence: L.C. Torres, Departamento de Pediatria, Laboratório de Investigação Médica (LIM 36), FM, USP, Av. Dr. Enéas C. Aguiar, 647, 05403-900 São Paulo, SP, Brasil. E-mail: Itorres@usp.br

Received April 14, 2010. Accepted October 19, 2010. Available online November 5, 2010. Published December $20,2010$. 
review showed that most genetic diseases were concomitant with primary immunodeficiency and RTS was included as a syndrome associated with phagocytic immunodeficiency.

Immunological evaluation of a 4-year-old RTS patient who presented suppurative otitis media and purulent rhinitis during the first years of life revealed low numbers of $T$ and $B$ cells and low levels of IgM and IgG antibodies to polysaccharide antigens. High serum levels of $\lg A$ antibodies, normal levels of IgG subclasses (IgG1, IgG2, IgG3, and IgG4) failed to respond to the Pneumovax vaccine (11). A Brazilian RTS patient with gum inflammation and bleeding was subjected to study of dental aspects (13). Additionally, this patient had recurrent respiratory infections in the first decade of life. Therefore, the authors conducted an immunological screening, which revealed normal levels of serum IgG and IgA antibodies, high IgM levels, normal anti-tetanus IgG levels, normal absolute values of total leukocytes in peripheral blood, and of lymphocytes, neutrophils, basophils, eosinophils and monocytes, as well as normal percentages of T CD4 ${ }^{+}$and T CD8 ${ }^{+}$cells (13). However, despite the high susceptibility of RTS patients to recurrent infections, there have been few reports about the evaluation of their immunocompetence $(10,11)$.

In the present paper, we report the results of an evaluation of the humoral immune response of 16 Brazilian RTS

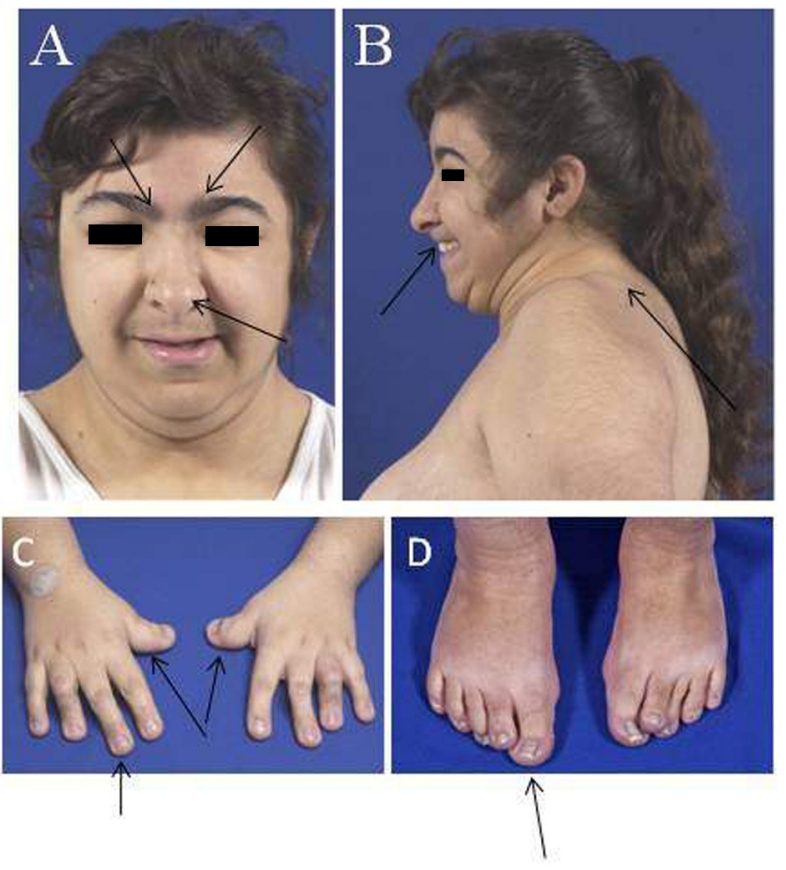

Figure 1. $A$, Patient 13 at the age of 23 years. Note sloping forehead, downslanting palpebral fissures, broad nasal bridge, and beaked nose with the nasal septum extending well below. $B$, Grimacing smile and congenital kyphosis. $C, D$, Hands and feet of patient 13 . Note that thumbs and halluces are radially deviated. $C$, Note the broad thumbs and $D$, broad halluces. Informed consent was obtained for publication of this figure. patients with recurrent respiratory infections. Taken together, the data obtained in this study suggest that RTS patients present B-cell dysregulation.

\section{Patients and Methods}

The diagnosis of RTS was first established by a pediatric geneticist using only clinical criteria (3). We studied a cohort of 16 unrelated RTS patients (4 males and 12 females, age range: 2-24 years). The study group consisted of children, adolescents and young adults with unequivocal RTS, defined here by the presence of the following four major clinical signs: short stature, typical facies, skeletal abnormalities, and mild to moderate mental retardation. The main features that allow a diagnosis of RTS are to be found in the face and limbs.

Figure 1 shows some clinical signs of one 23-year-old RTS patient. The facial appearance is striking: bushy and arched eyebrows, long eyelashes, downslanting palpebral fissures, broad nasal brigde, beaked nose with the nasal septum extending downwards, and grimacing smile (see Figure $1 A, B$ ). Broad thumbs and broad big toes are present in almost all cases. Thumbs and halluces are radially deviated in most patients (see Figure 1C,D).

Fifteen of our RTS patients had a normal karyotype at $450+$ band resolution, except patient 2 , who presented a de novo reciprocal translocation $\mathrm{t}(2 ; 16)$ (q36.3; p13.3) (14).

An additional criterion adopted for inclusion in this immunological study was the presence of recurrent infections. All patients presented recurrent respiratory infections in the first decade of life, as well as urinary tract infections (see Table 1). The patients had five or more episodes of recurrent respiratory infections per year in the first decade of life, and other clinical findings. Our RTS patients showed some of the 10 warning signs for the investigation of primary immunodeficiency in children, as described by the Brazilian Group for Immunodeficiency Disease - BRAGID (www. imunopediatria.org.br). We did not observe abnormally enlarged lymph nodes or splenomegaly in our RTS patients. There was no consanguinity in any family. The clinical and laboratory protocols were approved by the Ethics Committee for Analysis of Research Projects of the Hospital da Clínicas da Faculdade de Medicina da Universidade de São Paulo according to the Brazilian Ministry of Health's Regulatory Guidelines (Resolution 196/96 of the National Council of Health). The parents of the RTS patients and 16 healthy controls signed an informed consent form prior to inclusion in the study.

\section{Antibody determinations}

Serum levels of total $\lg G$, IgM, IgA, and IgG subclasses were determined by single radial immunodiffusion using a monoclonal antibody (mAb) obtained from Sigma-Aldrich, USA: clone I1011 for IgG, clone I1261 for IgA, and clone 18260 for IgM. For the IgG subclasses we used an mAb 
obtained from Unipath, UK: clone JL512 for IgG1, clone Gom1 for IgG2, clone ZG4 for IgG3, and clone GB7B for $\operatorname{lgG} 4$. The results were compared to those for a group of 330 Brazilian age-matched controls (15). We also determined salivary IgA levels in 9 patients using an ELISA technique with an mAb from Sigma-Aldrich, clone 10884. Samples of unstimulated whole saliva were obtained from 9 RTS patients.

The production of IgG antibodies against protein and polysaccharide antigens was evaluated in all patients for the tetanus toxoid and for the pneumococcal polysaccharide vaccine antigens, respectively. Patients were vaccinated with the 23-valent pneumococcal polysaccharide vaccine (Pneumo23 ${ }^{\circledR}$, Aventis Pasteur, France) and blood samples were collected before and 4 weeks after immunization. Antipneumococcal IgG antibodies against serotypes 1, 3, 4, 5, 6B, 9V, 14, 18C, 19F, and 23F (ATCC, USA) and IgM antibodies against pneumococcal serotypes $1,3,6 \mathrm{~B}, 9 \mathrm{~V}$, and 14 (ATCC) were determined using a modified ELISA protocol $(16,17)$. An adequate response to an individual polysaccharide was arbitrarily defined as a post-immunization antibody concentration equal to or higher than $1.3 \mathrm{mg} / \mathrm{mL}$ or a minimum 4-fold increase over the baseline value $(16,17)$.

All patients with RTS had received the tetanus toxoid vaccine according to the schedule recommended by the Brazilian Ministry of Health. Anti-tetanus toxoid IgG antibodies present in serum samples from RTS patients were measured by ELISA using tetanus toxoid as antigen (Butantan Institute, São Paulo, SP, Brazil). The antibodies against protein-tetanus toxoid are $\mathrm{T}$ cell dependent and antibodies against carbohydrates are $T$ cell independent.

Serum IgM antibody titers for the ABO group (isohemagglutinin) were measured by the agglutination technique using the Referencells-4 kit (Immucor, Belgium). The isohemagglutinins are natural antibodies of the IgM class, i.e., they are produced without stimulation.

\section{Determination of absolute number of $B$ cells and B-cell subtypes}

We also carried out immunophenotyping of blood lymphocyte samples using a FACSCalibur Becton Dickinson (BD, USA) flow cytometer at $488 \mathrm{~nm}$, and cell surface markers for human leukocytes. Peripheral blood samples were double or triple marked with anti-human $\mathrm{mAb}$ from Biosciences Pharmingen (USA): anti-CD45-PECy5 (clone HI30), anti-CD20-FITC (clone 2H7), anti-CD27-PE (clone MT271), anti-CD5-PECy5 (clone UCHT2), anti-IgM-PE (clone G20-127), or isotype control antibodies. All stained cells were analyzed with a FACSCAN flow cytometer using the Cellquest software (BD). The results were compared to those obtained with peripheral blood samples from 14 healthy adolescents and young adults.

\section{Apoptosis assay}

Apoptotic cells were measured in peripheral blood samples of 11 RTS patients and 11 healthy controls by flow cytometry after staining with annexin V-FITC and propidium iodide-PE using an apoptosis detection kit (BD) according to

Table 1. Main clinical findings of the 16 Brazilian patients with Rubinstein-Taybi syndrome.

\begin{tabular}{rrrlll}
\hline Patients & Gender & Age (years) & Ethnic background & $\begin{array}{c}\text { Recurrent respiratory } \\
\text { infections }\end{array}$ & $\begin{array}{c}\text { Other clinical } \\
\text { findings }\end{array}$ \\
\hline 1 & Female & 23.0 & Caucasian & 1 & 12 \\
2 & Female & 21.9 & Caucasian & 1 & 5 \\
3 & Male & 21.2 & African and Caucasian & $1,2,3,4$ & 9,12 \\
4 & Female & 14.1 & Caucasian & $1,2,3,4$ & $7,8,9,12,14$ \\
5 & Female & 12.8 & Caucasian & none & 12 \\
6 & Male & 11.4 & Caucasian & 1,3 & 6,10 \\
7 & Female & 8.7 & Caucasian & $1,3,4$ & 10 \\
8 & Female & 8.3 & Caucasian & 2,4 & 10 \\
9 & Female & 12.1 & Caucasian & $1,2,3,4$ & $7,8,9$ \\
10 & Female & 7.3 & Caucasian & $2,3,4$ & 8,9 \\
11 & Female & 6.6 & Caucasian & 2,3 & 9 \\
12 & Female & 3.4 & Caucasian & 1 & 11,13 \\
13 & Female & 23.0 & African and Caucasian & 1,3 & none \\
14 & Male & 12.8 & Caucasian & 1,2 & 9,10 \\
15 & Male & 20.2 & Caucasian & 2,4 & 12 \\
16 & Male & 2.3 & African and Caucasian & $2,3,4$ & 8,9 \\
\hline
\end{tabular}

1 = pneumonias; 2 = acute otitis media; 3 = tonsilitis; 4 = sinusitis; $5=$ pyoderma; 6 = meningitis; 7 = conjuctivitis; 8 = asthma; 9 = rhinitis; 10 = gastroenteritis with diarrhea; $11=$ anemia microcytica hypochromica; 12 = urinary tract infection; 13 = glaucoma; 14 = periodontitis . 
manufacturer instructions. B cells were labeled with an antiCD20-PECy5 monoclonal antibody (BD) and T cells with an anti-CD3-PECy5 monoclonal antibody (BD). All stained cells were analyzed with a FACSCalibur flow cytometer using the Cellquest software (BD) and the results were compared to those obtained with peripheral blood samples from 11 healthy young adults. Ten thousand events were acquired per sample.

\section{Statistical analysis}

Data regarding apoptosis and B-cell number were analyzed statistically by the paired or unpaired one-tailed Student $t$-test.

\section{Results}

Concentration of serum and salivary immunoglobulins

Normal or elevated serum IgG levels were observed in RTS patients (see Figure 2). Compared to normal values

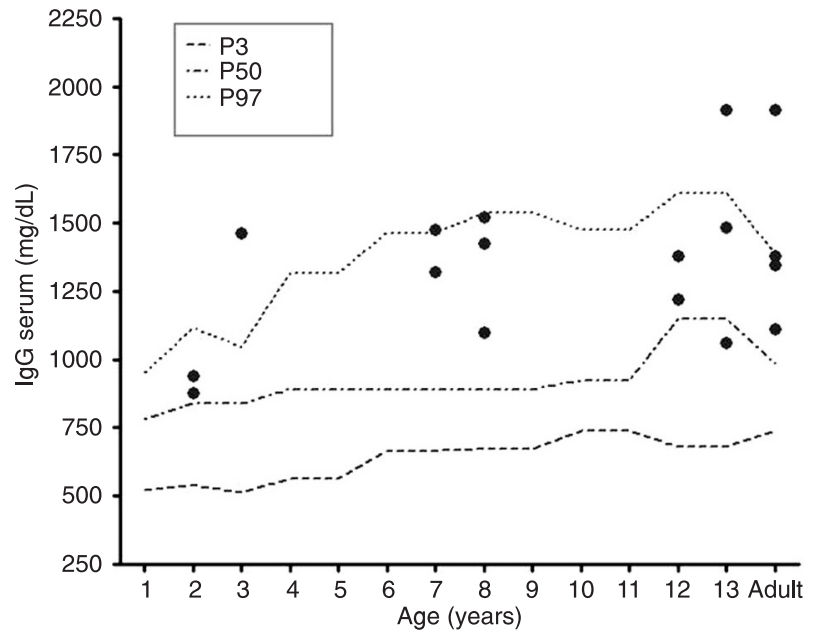

Figure 2. Serum IgG levels of patients with Rubinstein-Taybi syndrome compared to normal Brazilian references (15).
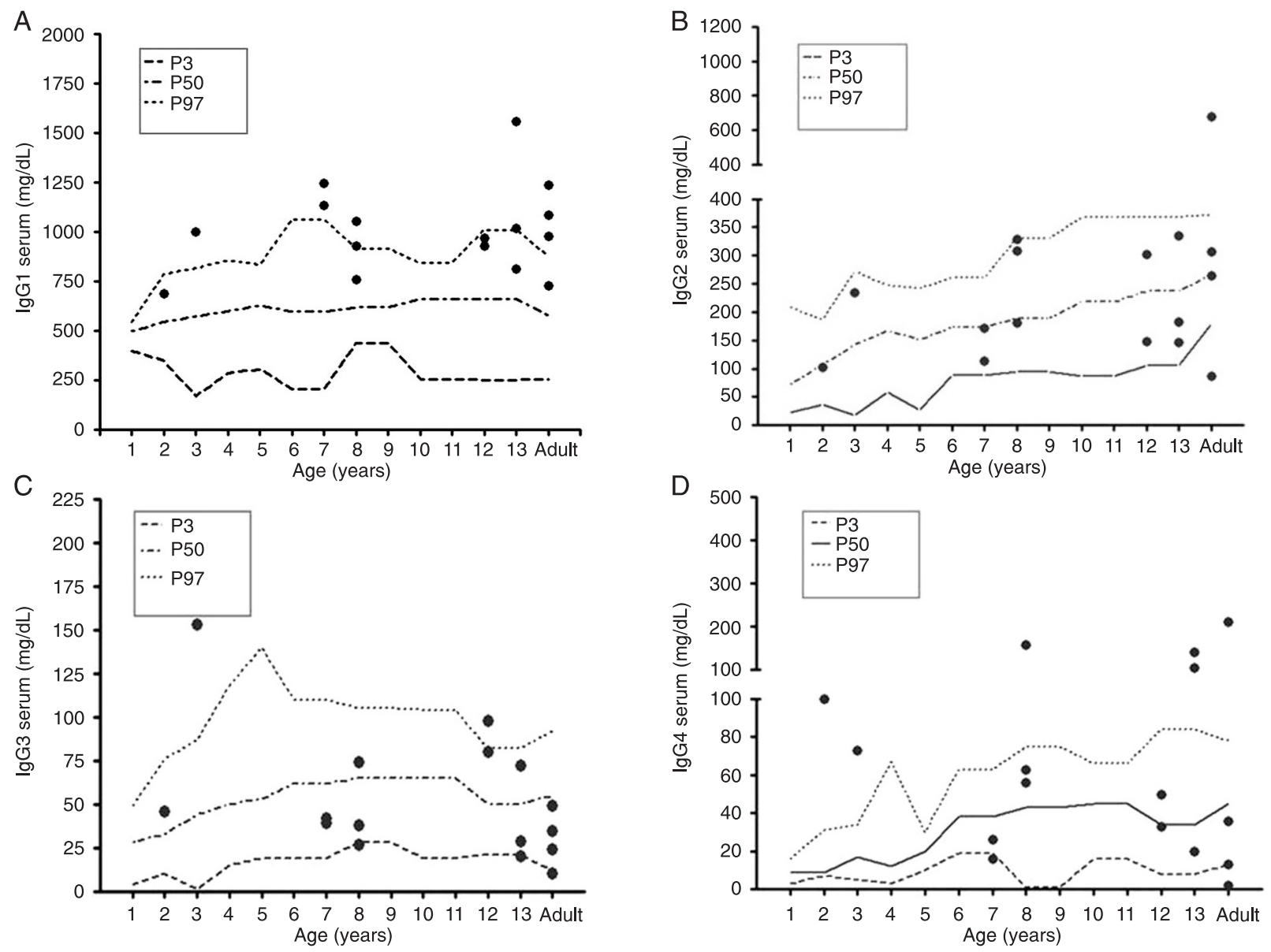

Figure 3. Subclass IgG levels of patients with Rubinstein-Taybi syndrome compared to normal Brazilian references (15). $A$, Serum subclass IgG1 levels. $B$, Serum subclass IgG2 levels. $C$, Serum subclass lgG3 levels. $D$, Serum subclass lgG4 levels. 
for the Brazilian population, 7/16 had serum IgG levels above the 97th percentile for age, and only one had IgG levels higher than $2000 \mathrm{mg} / \mathrm{dL}$. In 10 of the $16 \mathrm{RTS}$ patients studied, IgG1 levels were higher than the 97th percentile (see Figure 3A). Only one patient had serum IgG2 below the 3rd percentile (see Figure 3B). All patients had serum IgG3 levels within normal values and $6 / 15$ had serum IgG4 levels higher than the 97th percentile (see Figure $3 \mathrm{C}$ ). We measured the levels of antibody IgA in salivary and serum samples from RTS patients. All patients evaluated presented normal salivary and serum IgA levels (see Figure 4A and $B)$. Fifteen RTS patients had serum IgM levels above the 97th percentile, and 14/16 had IgM levels higher than 200 $\mathrm{mg} / \mathrm{dL}$, even in the absence of clinical signs of infection (see Figure 5).

\section{Anti-ABO titers}

We determined the titers of anti-ABO IgM antibodies in serum of RTS patients and of healthy control individuals in parallel. Most patients presented $64^{-1}$ to $128^{-1}$ anti-ABO IgM antibody titers. The anti-ABO IgM antibody titers of the RTS patients were equivalent to those of the healthy control individuals (data not shown).

\section{Anti-tetanus toxoid IgG antibody titers}

In $50 \%$ of the patients, the levels of IgG antibodies were considered to be protective and $50 \%$ responded after a booster tetanus toxoid dose (data not shown).

\section{Serum concentrations of pre- and post-immunization anti-pneumococcal IgG and IgM antibodies}

All RTS patients showed significantly higher post-immunization anti-pneumococcal IgG antibody levels compared to the pre-immunization levels of the serotypes evaluated. Serotypes 1 and 14 were 4-fold higher in all patients, even in the IgG2-deficient patient 1. All patients had post-vaccine levels of anti-pneumococcal IgG equal to or higher than 1.3 $\mathrm{mg} / \mathrm{mL}$ for the majority of the vaccine serotypes evaluated (see Table 2). The pre-immunization anti-pneumococcal IgM antibody levels for serotypes 1, 5, 6B, 9V, and 14 were higher in 12 RTS patients (see Table 3).

\section{Absolute numbers of total B cells and B-cell subsets in peripheral blood}

Flow cytometry analysis revealed significantly higher absolute numbers of total $\mathrm{B}$ cells $\left(\mathrm{CD} 2 \mathrm{O}^{+} \mathrm{CD} 45^{+}\right)$, naive $\mathrm{B}$ cells $\left(\mathrm{CD} 20^{+} \mathrm{CD} 27^{-}\right)$, memory $\mathrm{B}$ cells $\left(\mathrm{CD} 20^{+} \mathrm{CD} 27^{+}\right), \mathrm{B} 1$ subset cells $\left(\mathrm{CD} 2 \mathrm{O}^{+} \mathrm{CD}^{+}\right)$and cell surface immunoglobulin $\mathrm{M}\left(\mathrm{slgM}^{+}\right) \mathrm{B}$ cells in the peripheral blood of RTS patients compared to healthy controls (see Figure 6A).

In percentile terms, there were significant differences only in the population of $\mathrm{B} 1$ subsets and $\operatorname{sigM}^{+} \mathrm{B}$ cells of the patients (data not shown). The other subpopulations of $B$ cells did not present significant differences in percentile values compared to healthy controls (data not shown).
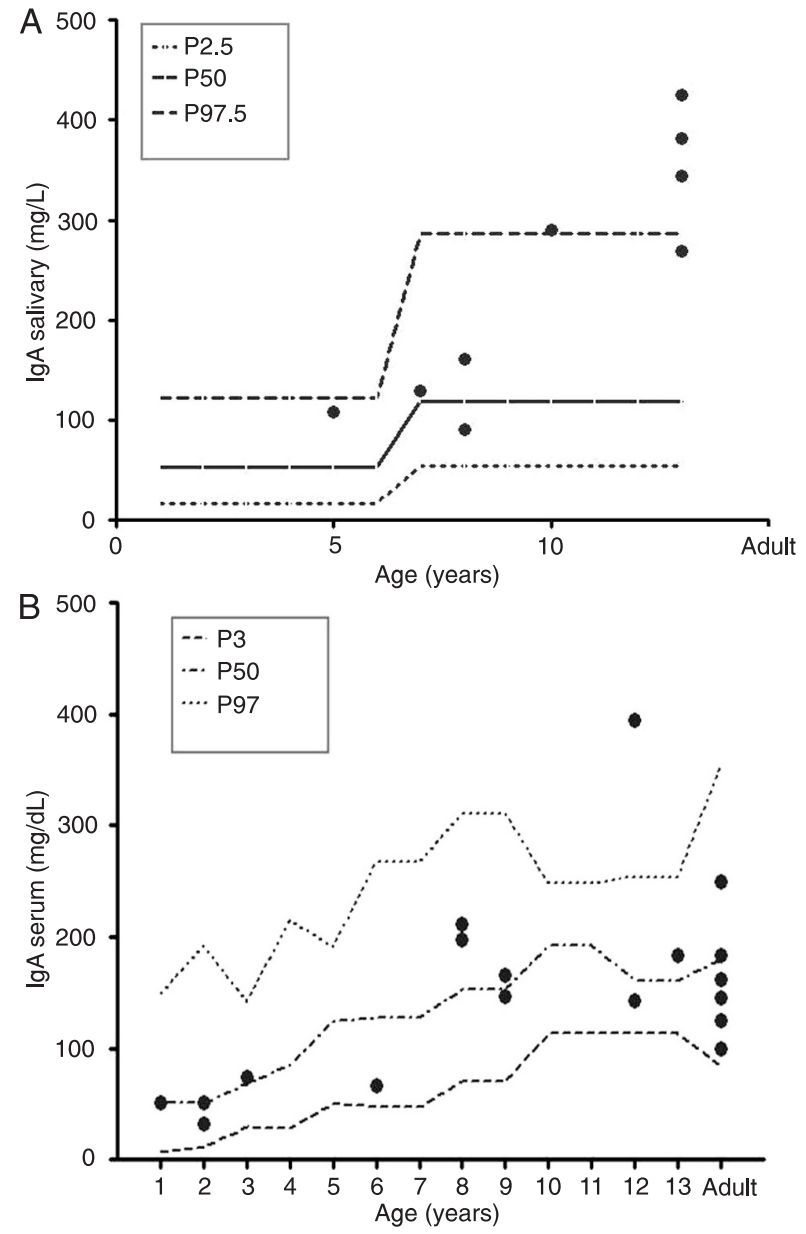

Figure 4. Salivary (A) and serum (B) IgA levels of patients with Rubinstein-Taybi syndrome (RTS) compared to normal Brazilian references (15). Note: of the 16 RTS patients evaluated, only 9 showed up to the lab for saliva collection.

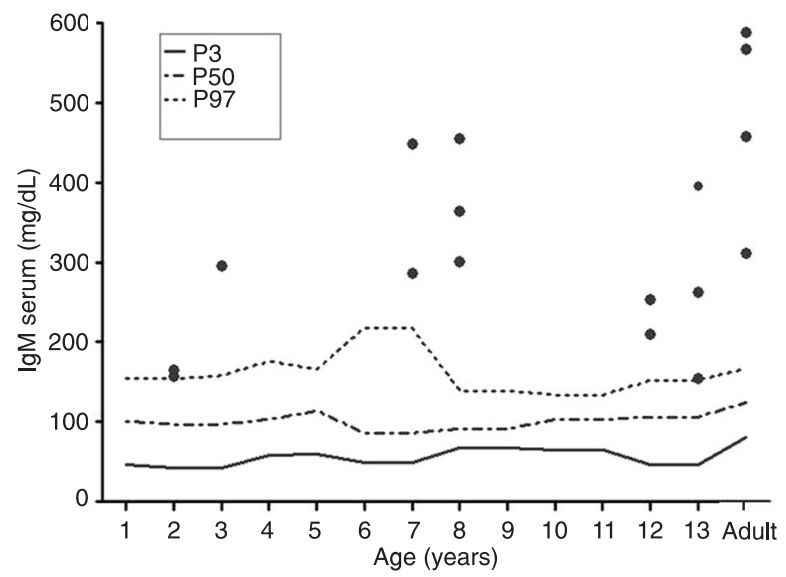

Figure 5. Serum IgM levels of patients with Rubinstein-Taybi syndrome compared to normal Brazilian references (27). 


\section{Percentile values of apoptosis in total leukocytes and B cells in peripheral blood}

We perfomed the evaluation of apoptosis in only 11 of the 16 RTS patients because 5 did not appear for collection of blood samples. Nine of these 11 RTS patients presented higher percentages of apoptotic cells in peripheral blood samples compared to healthy controls, in determinations run in parallel. A higher rate of apoptosis was observed in the population of B cells in 9 of the 11 RTS patients evaluated (see Figure $6 \mathrm{~B}$ ), whereas $2 \mathrm{RTS}$ patients were similar to control subjects (analysis run in parallel).

\section{Discussion}

Regarding the humoral immune response, the main findings in RTS patients were high concentrations of serum IgM and IgG1 subclasses compared to individual healthy controls, according to age group and in the absence of clinical signs of infection. Only one patient had serum IgG2 below the 3rd percentile. Freitas et al. (13) described another Brazilian patient with RTS with periodontal diseases and recurrent respiratory infections and with high levels of serum total IgM. Xu et al. (18) measured immunoglobulin levels in mice in which they had induced inactivation of the CBP or p300 alleles. The mice with CBP inactivation had 2-fold higher IgG3 and IgM levels compared to controls, whereas the mice with p300 inactivation had normal amounts of IgG3 and IgM (18). In murine models, the loss of CBP in B cells leads to higher levels of $\lg G 3$ and $\lg M(18)$. These findings suggest that the serum concentration of IgM can be regulated by activation of CREB protein when it is phosphorylated by protein kinase $A$ and interacts with the KIX region of CBP (1921). Immunophenotyping of $B$ cells showed that the absolute numbers of naive $B$ cells $\left(\right.$ CD20 ${ }^{+}$CD27-), total B cells (CD20 ${ }^{+}$CD $45^{+}$) and memory $B$ cells $\left(\mathrm{CD} 27^{+} \mathrm{CD} 45^{+}\right)$were higher in all of our RTS patients. B1 subsets $\left(C D 20^{+} \mathrm{CD}^{+}\right)$and slgM $^{+}$B lymphocytes were higher both in percent and in absolute number. We demonstrated here that differences in the expression of the total B cells and their subpopulations (naive, memory, $\mathrm{B} 1$, and $\operatorname{sigM}^{+} \mathrm{B}$ cells) were statistically significant $(P<0.005)$ between RTS patients
Table 2. Response to immunization with the 23-valent pneumococcal polysaccharide vaccine: pre-immunization and post-immunization pneumococcal antibody titers in patients with Rubinstein-Taybi syndrome.

\begin{tabular}{|c|c|c|c|c|c|c|c|c|c|c|}
\hline & \multicolumn{10}{|c|}{ Serotype and antibody titer } \\
\hline & 1 & 3 & 4 & 5 & $6 \mathrm{~B}$ & $9 \mathrm{~V}$ & 14 & $18 \mathrm{C}$ & $19 \mathrm{~F}$ & $23 \mathrm{~F}$ \\
\hline \multicolumn{11}{|c|}{ Patient 1} \\
\hline Pre & 0.4 & 1.0 & 0.4 & 0.5 & 0.7 & 1.7 & 1.7 & 0.6 & 1.1 & 0.6 \\
\hline Post & 9.4 & 1.4 & 10.3 & 0.8 & 3.0 & 8.9 & 23.1 & 4.2 & 4.9 & 1.5 \\
\hline \multicolumn{11}{|c|}{ Patient 2} \\
\hline Pre & 5.0 & 3.3 & 6.1 & 2.5 & 3.9 & 1.2 & 2.5 & 2.2 & 10.8 & 2.5 \\
\hline Post & 43.0 & 3.2 & 7.9 & 11.4 & 6.0 & $>50.0$ & 14.5 & 4.2 & 33.7 & 5.0 \\
\hline \multicolumn{11}{|c|}{ Patient 3} \\
\hline Pre & 2.6 & 2.8 & 2.4 & 5.7 & 5.7 & 3.1 & 3.8 & 1.9 & 7.3 & 4.6 \\
\hline Post & 31.0 & 5.9 & 7.0 & 46.4 & 12.9 & 6.0 & 26.1 & 10.7 & 8.4 & 4.9 \\
\hline \multicolumn{11}{|c|}{ Patient 4} \\
\hline Pre & 2.6 & 2.8 & 4.0 & 4.6 & 2.7 & 6.4 & 7.8 & 1.6 & 12.1 & 6.6 \\
\hline Post & 31.0 & 5.9 & 9.6 & 9.9 & 14.8 & 20.7 & 19.2 & 6.1 & 24.3 & 8.5 \\
\hline \multicolumn{11}{|c|}{ Patient 5} \\
\hline Pre & 3.3 & 0.8 & 0.8 & 0.8 & 1.7 & 0.8 & 1.7 & 1.6 & 5.1 & 2.5 \\
\hline Post & 8.2 & 1.0 & 3.3 & 8.2 & 3.1 & 3.9 & 4.6 & 5.8 & 21.5 & 2.9 \\
\hline \multicolumn{11}{|c|}{ Patient 6} \\
\hline Pre & 0.5 & 0.9 & 0.2 & 1.9 & 0.8 & 0.5 & 1.9 & 0.3 & 1.1 & 0.5 \\
\hline Post & $>50.0$ & 1.6 & 4.5 & 8.1 & 1.7 & 4.6 & $>50.0$ & 3.9 & 10.5 & 5.8 \\
\hline \multicolumn{11}{|c|}{ Patient 7} \\
\hline Pre & 0.5 & 0.9 & 0.3 & 0.6 & 5.5 & 0.7 & 1.5 & 0.5 & 1.4 & 1.4 \\
\hline Post & 6.6 & 2.9 & 2.0 & 2.5 & 6.4 & 2.9 & 9.4 & 5.1 & 5.5 & 2.6 \\
\hline \multicolumn{11}{|c|}{ Patient 8} \\
\hline Pre & 0.6 & 1.9 & 5.5 & 0.7 & 3.2 & 0.4 & 1.8 & 0.4 & 1.6 & 0.8 \\
\hline Post & 3.8 & 3.0 & 4.8 & 3.8 & 3.8 & 8.8 & 2.1 & 2.6 & 2.7 & 0.9 \\
\hline \multicolumn{11}{|c|}{ Patient 9} \\
\hline Pre & 0.6 & 0.9 & 0.5 & 0.9 & 0.8 & 0.4 & 1.3 & 0.4 & 1.9 & 0.9 \\
\hline Post & 10.0 & 2.2 & 1.6 & 1.3 & 1.4 & 14.5 & 25.3 & 2.6 & 2.5 & 1.4 \\
\hline \multicolumn{11}{|c|}{ Patient 10} \\
\hline Pre & 0.7 & 1.2 & 0.5 & 1.2 & 0.8 & 6.3 & 3.4 & 0.4 & 1.8 & 0.9 \\
\hline Post & 2.9 & 1.6 & 1.5 & 1.9 & 0.8 & 5.9 & 21.6 & 1.3 & 2.7 & 1.2 \\
\hline \multicolumn{11}{|c|}{ Patient 11} \\
\hline Pre & 1.1 & 3.5 & 0.5 & 1.0 & 1.0 & 0.6 & 2.5 & 11.3 & 1.9 & 1.0 \\
\hline Post & 5.4 & 4.8 & 1.8 & 2.5 & 0.8 & 9.7 & 7.2 & 9.9 & 2.9 & 1.0 \\
\hline \multicolumn{11}{|c|}{ Patient 12} \\
\hline Pre & \# & $\#$ & \# & \# & $\#$ & $\#$ & $\#$ & \# & \# & \# \\
\hline Post & 4.3 & 0.6 & $\#$ & 1.3 & 0.3 & 4.2 & 2.8 & \# & \# & \# \\
\hline \multicolumn{11}{|c|}{ Patient 13} \\
\hline Pre & 0.4 & 0.5 & \# & 0.2 & 0.2 & 0.1 & 0.8 & \# & \# & \# \\
\hline Post & 11.2 & 1.6 & $\#$ & 2.4 & 0.4 & 16.8 & 5.5 & $\#$ & \# & \# \\
\hline \multicolumn{11}{|c|}{ Patient 14} \\
\hline Pre & 1.4 & 1.2 & \# & 1.2 & 5.3 & 1.0 & 1.2 & \# & \# & \# \\
\hline Post & 2.6 & 3.8 & \# & 1.6 & 2.3 & 1.6 & 5.6 & \# & \# & \# \\
\hline \multicolumn{11}{|c|}{ Patient 15} \\
\hline Pre & 1.1 & 0.5 & $\#$ & 0.6 & 0.4 & 2.9 & 0.7 & \# & \# & \# \\
\hline Post & 5.7 & 4.5 & \# & 5.2 & 17.2 & 12.7 & 49.4 & \# & \# & \# \\
\hline \multicolumn{11}{|c|}{ Patient 16} \\
\hline Pre & 1.8 & 1.6 & $\#$ & 0.5 & 0.7 & 6.5 & 1.7 & \# & \# & $\#$ \\
\hline Post & 2.5 & 5.4 & $\#$ & 3.4 & 4.2 & 14.1 & 7.3 & \# & \# & $\#$ \\
\hline
\end{tabular}

Post-immunization levels $\geq 1.3 \mathrm{mg} / \mathrm{mL}$ or a 4 -fold increase of baseline value arbitrarily defined according to references 16 and 17 . \#Serum samples were insufficient for the determination of antibody titers. 
Table 3. Pre-immunization and post-immunization anti-pneumococcal IgM antibody levels $(\mathrm{mg} / \mathrm{mL})$ for the different serotypes (1, $5,6 \mathrm{~B}, 9 \mathrm{~V}$, and 14).

\begin{tabular}{|c|c|c|c|c|c|}
\hline & \multicolumn{5}{|c|}{ Serotype and antibody titer } \\
\hline & 1 & 5 & $6 B$ & $9 \mathrm{~V}$ & 14 \\
\hline \multicolumn{6}{|c|}{ Patient 1} \\
\hline Pre & 5.0 & 12.3 & 10.5 & 5.9 & 5.1 \\
\hline Post & 5.7 & 13.8 & 11.0 & 5.2 & 5.3 \\
\hline \multicolumn{6}{|c|}{ Patient 2} \\
\hline Pre & 3.0 & 5.6 & 4.8 & 2.4 & 2.8 \\
\hline Post & 14.1 & 10.5 & 7.4 & 9.9 & 4.2 \\
\hline \multicolumn{6}{|c|}{ Patient 3} \\
\hline Pre & 3.7 & 7.6 & 6.4 & 3.2 & 4.5 \\
\hline Post & 4.7 & 10.9 & 6.6 & 5.2 & 5.2 \\
\hline \multicolumn{6}{|c|}{ Patient 4} \\
\hline Pre & 1.0 & 2.6 & 1.9 & 1.3 & 1.1 \\
\hline Post & 2.8 & 4.7 & 2.4 & 4.3 & 1.2 \\
\hline \multicolumn{6}{|c|}{ Patient 5} \\
\hline Pre & 1.8 & 3.7 & 2.9 & 1.8 & 2.0 \\
\hline Post & 5.7 & 8.1 & 3.9 & 4.5 & 3.2 \\
\hline \multicolumn{6}{|c|}{ Patient 6} \\
\hline Pre & 2.4 & 6.1 & 5.9 & 2.2 & 2.8 \\
\hline Post & 3.2 & 6.4 & 4.4 & 3.4 & 3.3 \\
\hline \multicolumn{6}{|c|}{ Patient 7} \\
\hline Pre & 1.8 & 4.5 & 3.8 & 1.9 & 2.0 \\
\hline Post & 2.6 & 5.5 & 4.6 & 2.5 & 2.2 \\
\hline \multicolumn{6}{|c|}{ Patient 8} \\
\hline Pre & 1.7 & 4.2 & 3.6 & 1.8 & 2.1 \\
\hline Post & 2.5 & 5.4 & 4.5 & 4.3 & 3.2 \\
\hline \multicolumn{6}{|c|}{ Patient 9} \\
\hline Pre & 5.3 & 13.2 & 11.1 & 6.4 & 6.3 \\
\hline Post & 7.5 & 18.9 & 14.6 & 8.7 & 10.9 \\
\hline \multicolumn{6}{|c|}{ Patient 10} \\
\hline Pre & 6.2 & 14.7 & 11.2 & 6.0 & 4.4 \\
\hline Post & 7.6 & 19.8 & 14.2 & 12.3 & 5.7 \\
\hline \multicolumn{6}{|c|}{ Patient 11} \\
\hline Pre & 3.9 & 8.2 & 6.3 & 3.2 & 3.7 \\
\hline Post & 5.3 & 10.9 & 6.0 & 7.5 & 4.6 \\
\hline \multicolumn{6}{|c|}{ Patient 12} \\
\hline Pre & 3.6 & 4.0 & 3.6 & 3.8 & 4.2 \\
\hline Post & 3.7 & 4.8 & 4.1 & 3.7 & 5.7 \\
\hline \multicolumn{6}{|c|}{ Patient 13} \\
\hline Pre & 2.5 & 2.4 & 3.6 & 4.2 & 2.9 \\
\hline Post & 3.5 & 3.3 & 4.4 & 4.8 & 3.3 \\
\hline \multicolumn{6}{|c|}{ Patient 14} \\
\hline Pre & 2.0 & 1.8 & 2.6 & 2.9 & 2.3 \\
\hline Post & 2.6 & 2.9 & 2.4 & 2.6 & 2.4 \\
\hline \multicolumn{6}{|c|}{ Patient 15} \\
\hline Pre & 2.0 & 1.9 & 2.7 & 2.8 & 2.4 \\
\hline Post & 2.6 & 3.5 & 3.3 & 3.1 & 3.0 \\
\hline \multicolumn{6}{|c|}{ Patient 16} \\
\hline Pre & 1.1 & 1.1 & 1.5 & 1.5 & 1.2 \\
\hline Post & 1.1 & 1.2 & 1.5 & 1.7 & 1.4 \\
\hline
\end{tabular}
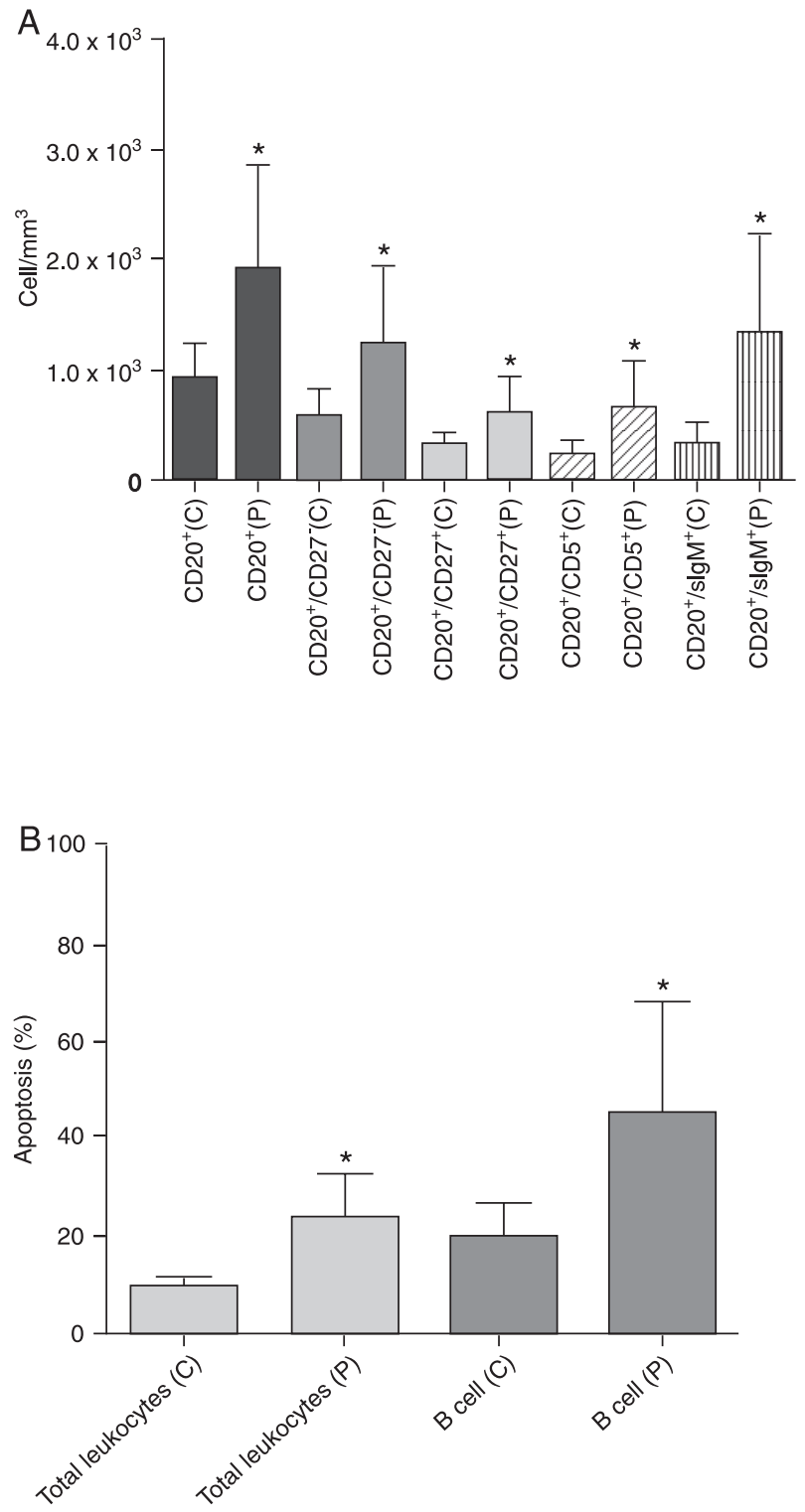

Figure 6. A, Flow cytometry analysis of the absolute number of total, subsets and $\operatorname{slgM}^{+} \mathrm{B}$ lymphocytes in peripheral blood samples from patients with Rubinstein-Taybi syndrome (RTS; N $=16)$ compared to healthy controls $(N=16)$. $B$, High percentage of apoptosis in the total leukocytes and B cells of RTS patients ( $N$ $=11$ ) compared to healthy controls $(N=11)$. Data are reported as means $\pm \mathrm{SD}$. $\mathrm{P}=\mathrm{RTS}$ patients; $\mathrm{C}=$ healthy controls; slgM = cellular surface immunoglobulin $\mathrm{M}$. ${ }^{*} \mathrm{P}<0.005$, compared to healthy controls (Student $t$-test). 
and control subjects. These findings suggest that the lymphocytosis detected in patients predominantly involves $B$ lymphocytes. Based on the literature, we know that both $C B P$ and $p 300$ genes are essential to maintain B-cell homeostasis in peripheral blood and that $C B P$, in particular, is involved in the normal differentiation of these cells $(22,23)$. In $45-56 \%$ of patients with RTS, there is association with mutations of the CREBBP gene (7). Genetic analyses of the 16 RTS patients in the present study are in progress. Preliminary data have demonstrated mutation or deletion in the CBP gene in 7 of the 16 RTS patients.

The patients studied here, had presented recurrent respiratory infections mainly in the first decade of life. All RTS patients presented post-vaccinal levels of antipolysaccharide pneumococcal IgG considered to be protective against most of the 10 serotypes of the 23 -valent pneumococcal vaccine tested. The protective antibody responses to polysaccharides observed in our study are in contrast to the findings of Naimi et al. (24) who showed a defective anti-polysaccharide antibody response in three RTS patients. Our results showed that RTS patients did not present defects in the production of antibodies against both T-dependent (anti-tetanus toxoid lgG) and T-independent (anti-pneumococcal lgG) antigens.

The recurrent respiratory infections of our RTS patients were responsive to penicillin derivatives and were most probably caused by encapsulated bacteria, mainly pneumococci. Antibodies are well known to be critical for protective immunity against pneumococcal infections (25). How can we explain a normal antibody response of our RTS patients to pneumococcal polysaccharides despite their susceptibility to respiratory bacterial infections? One possibility is a defect in the activation of NF- $\kappa B$ by CBP. Some investigators have suggested that recruitment of CBP to p65-containing NF- $\mathrm{KB}$ complexes is essential for transcriptional activity, and that this interaction between $\mathrm{p} 65$ and $\mathrm{CBP}$ is a prerequisite for efficient transcription by NF-KB (19-21).

Our RTS patients also had a reduction of infectious episodes with age and they did not present quantitative deficiencies in immunoglobulin levels, or in specific antibody production to both polysaccharide and protein antigens, or in the percent and the absolute number of B cells. In addition to the importance of the CBP gene for the transcriptional activity of NF-kB, the hypothesis exists that the loss of CBP in patients with RTS can interfere with a complete activation of NF-kB and thus impair the immune response directed against extracellular pathogens that are dependent on the pathway of NF-kB transcription. Another possible explanation of the recurrent respiratory infections by extracellular bacteria that infected our patients even in the presence of protective levels of specific antibodies would be that the production of anti-lgG pneumococcal polysaccharides is not effective in eliminating the pathogen due to low avidity of these antibodies for the antigen. This involves the maturation of the affinity of antibodies for antigens that occurs through cellular signaling by costimulatory molecules and also by the action of cytokines from the interaction of activated $T$ and $B$ lymphocytes.

Our results demonstrated a persistent leukocytosis in RTS patients even in the absence of clinical signs of infection $\left(11,000\right.$ to $\left.26,000 / \mathrm{mm}^{3}\right)$ in 12 of 16 subjects (data not shown). To determine whether the cause of persistent leukocytosis was linked to defects in the intrinsic pathway of cellular apoptosis in RTS patients, we determined the rate of apoptosis in their peripheral blood and detected a higher percentage of apoptosis in total leukocytes and B cells of 9 of 11 RTS patients compared to healthy controls. Studies in murine models suggest that the high percentage of B-cell apoptosis in our patients with RTS is due to decreased expression of protein BCL-2 by these cells. $B C L-2$ is the first member of the family of five anti-apoptotic proteins (BCL-2, BCL-XL, BfL-1, and McL-1) that resides in the mitochondria and in the endoplasmic reticulum. Some investigators have shown that the CREBBP gene functions as an important factor for survival and protection against cellular apoptosis $(26,27)$. In transgenic mice that express a dominant-negative CREB construct, there was higher apoptosis after activation of these cells $(26,27)$. Reduced levels of $B C L-2$ protein were observed in the $B$ lymphocytes of these transgenic mice $(23,27)$.

Xiang et al. (28) have shown that mutations in CREB result in significantly reduced protein levels and gene expression of BCL-2 in B lymphocytes, and BCL-2 is essential for the survival of $B$ cells. Thus, CREB is essential for basal expression of BCL-2 and to increase the BCL-2 levels after activation of $B$ cells (28). Wilson et al. (29) have demonstrated that CREB is an important transcription factor of gene BCL-2 in B cells, and that after the activation of these cells, CREB interacts with the BCL-2 promoter, enabling the gene expression of BCL-2, which culminates in the protection of the cells from apoptosis. How to explain the persistent leukocytosis (lymphocytosis) with the high rate of apoptosis of total leukocytes and B lymphocytes observed in patients with RTS? We know that BCL-2 has an important role in saving the cells from apoptosis, but also in inhibiting cell proliferation. Thus, reduced BCL-2 levels promote an increase of apoptosis and also of cell proliferation (leukocytosis - lymphocytosis). Some investigators have shown that BCL-2 can inhibit apoptosis and cell proliferation by regulating the expression of another gene called c-MYC (30). We hypothesized that the patients with RTS had reduced levels of $\mathrm{Bcl}-2$, promoting an increased percentage of apoptosis and of cellular proliferation.

When evaluating the humoral immune response of 16 RTS patients, we demonstrated that most had normal levels of total serum lgG, IgG2 subclass and anti-polysaccharide $\lg \mathrm{G}$ antibodies. However, they presented high $\lg \mathrm{M}$ and lgG1 concentrations. The only patient with low lgG2 levels presented a normal anti-polysaccharide antibody response. We do not consider this patient to have antibody deficiency. 
Despite an apparently normal humoral immunity, the patients presented recurrent respiratory infections caused by extracellular bacteria.

In conclusion, the RTS patients evaluated in the present study did not show deficiency of the humoral immune response. However, our findings showed signs of B cell dysregulation in these patients. Further investigation of the cellular and molecular mechanisms involved in the immune response and in the regulation of $\mathrm{B}$-cell apoptosis

\section{References}

1. Rubinstein $\mathrm{JH}$. Broad thumb-hallux (Rubinstein-Taybi) syndrome 1957-1988. Am J Med Genet Suppl 1990; 6: 3-16.

2. Hamosh A, Scott AF, Amberger J, Bocchini C, Valle D, McKusick VA. Online Mendelian Inheritance in Man (OMIM), a knowledgebase of human genes and genetic disorders. Nucleic Acids Res 2002; 30: 52-55.

3. Hennekam RC, Stevens CA, Van de Kamp JJ. Etiology and recurrence risk in Rubinstein-Taybi syndrome. Am J Med Genet Supp/ 1990; 6: 56-64.

4. Hennekam RC. Rubinstein-Taybi syndrome. Eur J Hum Genet 2006; 14: 981-985.

5. Stevens CA, Carey JC, Blackburn BL. Rubinstein-Taybi syndrome: a natural history study. Am J Med Genet Suppl 1990; 6: 30-37.

6. Lacombe D, Saura R, Taine L, Battin J. Confirmation of assignment of a locus for Rubinstein-Taybi syndrome gene to 16p13.3. Am J Med Genet 1992; 44: 126-128.

7. Bartsch O, Schmidt S, Richter M, Morlot S, Seemanova E, Wiebe $\mathrm{G}$, et al. DNA sequencing of CREBBP demonstrates mutations in $56 \%$ of patients with Rubinstein-Taybi syndrome (RSTS) and in another patient with incomplete RSTS. Hum Genet 2005; 117: 485-493.

8. Roelfsema JH, White SJ, Ariyurek Y, Bartholdi D, Niedrist D, Papadia F, et al. Genetic heterogeneity in Rubinstein-Taybi syndrome: mutations in both the CBP and EP300 genes cause disease. Am J Hum Genet 2005; 76: 572-580.

9. Foley P, Bunyan D, Stratton J, Dillon M, Lynch SA. Further case of Rubinstein-Taybi syndrome due to a deletion in EP300. Am J Med Genet A 2009; 149A: 997-1000.

10. Rivas F, Fragoso R, Ramos-Zepeda R, Vaca G, Hernandez A, Gonzalez-Quiroga G, et al. Deficient cell immunity and mild intermittent hyperaminoacidemia in a patient with the Rubinstein-Taybi syndrome. Acta Paediatr Scand 1980; 69: 123-125.

11. Villella A, Bialostocky D, Lori E, Meyerson H, Hostoffer RW. Rubinstein-Taybi syndrome with humoral and cellular defects: a case report. Arch Dis Child 2000; 83: 360-361.

12. Ming JE, Stiehm ER, Graham JM Jr. Immunodeficiency as a component of recognizable syndromes. Am J Med Genet 1996; 66: 378-398.

13. Freitas NM, Imbronito AV, La Scala CS, Lotufo RF, Pustiglioni FE. Periodontal disease in a Rubinstein-Taybi syndrome patient: case report. Int J Paediatr Dent 2006; 16: 292-296.

14. Torres LC, de Lourdes Lopes CM, Delboni TP, Okay TS, Carneiro-Sampaio M, Sugayama S. Rubinstein-Taybi syndrome: a female patient with a de novo reciprocal translocation $\mathrm{t}(2 ; 16)(\mathrm{q} 36.3 ; \mathrm{p} 13.3)$ and dysgranulopoiesis. Clinics are necessary to clarify the alterations observed in the affected patients.

\section{Acknowledgments}

The authors thank the patients, their families, the Brazilian RTS support group (http://www.artsbrasil.org.br), as well as FAPESP (\#02/05880-4 and \#07/56491-1) for financial support.
2010; 65: 107-109.

15. Naspitz CK, Solé D, Carneiro-Sampaio MM, Gonzalez CH. Serum levels of $\lg G$, IgM, and $\lg A$ in healthy Brazilian children. J Pediatr 1982; 62: 121-126.

16. Sorensen RU, Hidalgo H, Moore C, Leiva LE. Post-immunization pneumococcal antibody titers and IgG subclasses. Pediatr Pulmonol 1996; 22: 167-173.

17. Sorensen RU, Leiva LE, Javier FC III, Sacerdote DM, Bradford N, Butler B, et al. Influence of age on the response to Streptococcus pneumoniae vaccine in patients with recurrent infections and normal immunoglobulin concentrations. J Allergy Clin Immunol 1998; 102: 215-221.

18. Xu W, Fukuyama T, Ney PA, Wang D, Rehg J, Boyd K, et al. Global transcriptional coactivators CREB-binding protein and p300 are highly essential collectively but not individually in peripheral B cells. Blood 2006; 107: 4407-4416.

19. Zhong H, Voll RE, Ghosh S. Phosphorylation of NF-kappa B p65 by PKA stimulates transcriptional activity by promoting a novel bivalent interaction with the coactivator CBP/p300. Mol Cell 1998; 1: 661-671.

20. Parker D, Ferreri K, Nakajima T, LaMorte VJ, Evans R, Koerber SC, et al. Phosphorylation of CREB at Ser-133 induces complex formation with CREB-binding protein via a direct mechanism. Mol Cell Biol 1996; 16: 694-703.

21. Gerritsen ME, Williams AJ, Neish AS, Moore S, Shi Y, Collins T. CREB-binding protein/p300 are transcriptional coactivators of p65. Proc Natl Acad Sci U S A 1997; 94: 2927-2932.

22. Rebel VI, Kung AL, Tanner EA, Yang H, Bronson RT, Livingston DM. Distinct roles for CREB-binding protein and p300 in hematopoietic stem cell self-renewal. Proc Natl Acad Sci U S A 2002; 99: 14789-14794.

23. Zhang $\mathrm{CY}, \mathrm{Wu} \mathrm{YL}$, Boxer LM. Impaired proliferation and survival of activated $B$ cells in transgenic mice that express a dominant-negative cAMP-response element-binding protein transcription factor in B cells. J Biol Chem 2002; 277: 4835948365.

24. Naimi DR, Munoz J, Rubinstein J, Hostoffer RW Jr. Rubinstein-Taybi syndrome: an immune deficiency as a cause for recurrent infections. Allergy Asthma Proc 2006; 27: 281284.

25. Carneiro-Sampaio M, Coutinho A. Immunity to microbes: lessons from primary immunodeficiencies. Infect Immun 2007; 75: 1545-1555.

26. Barton K, Muthusamy N, Chanyangam M, Fischer C, Clendenin C, Leiden JM. Defective thymocyte proliferation and IL-2 production in transgenic mice expressing a dominant- 
negative form of CREB. Nature 1996; 379: 81-85.

27. Zhang F, Rincon M, Flavell RA, Aune TM. Defective Th function induced by a dominant-negative cAMP response element binding protein mutation is reversed by $\mathrm{Bcl}-2$. $J$ Immunol 2000; 165: 1762-1770.

28. Xiang H, Wang J, Boxer LM. Role of the cyclic AMP response element in the bcl-2 promoter in the regulation of endogenous $\mathrm{Bcl}-2$ expression and apoptosis in murine $\mathrm{B}$ cells. Mol Cell Biol 2006; 26: 8599-8606.
29. Wilson BE, Mochon E, Boxer LM. Induction of bcl-2 expression by phosphorylated CREB proteins during B-cell activation and rescue from apoptosis. Mol Cell Biol 1996; 16: $5546-5556$.

30. Arcinas M, Heckman CA, Mehew JW, Boxer LM. Molecular mechanisms of transcriptional control of bcl-2 and c-myc in follicular and transformed lymphoma. Cancer Res 2001; 61: 5202-5206. 